\title{
Cognitive frailty among Malaysian older adults: baseline findings from the LRGS TUA cohort study
}

This article was published in the following Dove Press journal:

Clinical Interventions in Aging

\section{Nurul Fatin Malek Rivan' \\ Suzana Shahar ${ }^{2}$ \\ Nor Fadilah Rajab ${ }^{3}$ \\ Devinder Kaur Ajit Singh ${ }^{4}$ \\ Normah Che Din ${ }^{5}$ \\ Mahadzir Hazlina ${ }^{6}$ \\ Tengku Aizan Tengku Abdul \\ Hamid $^{7}$}

\begin{abstract}
'Nutritional Sciences Programme and Centre for Healthy Ageing and Wellness (H-CARE), Faculty of Health Sciences, Universiti Kebangsaan Malaysia, 50300 Kuala Lumpur, Malaysia; ${ }^{2}$ Dietetics Programme and Centre for Healthy Ageing and Wellness (H-CARE), Faculty of Health Sciences, Universiti Kebangsaan Malaysia, 50300 Kuala Lumpur, Malaysia; ${ }^{3}$ Biomedical Science Programme, School of Diagnostic and Applied Health Sciences, Faculty of Health Sciences, Universiti Kebangsaan Malaysia, 50300 Kuala Lumpur, Malaysia;

${ }^{4}$ Physiotherapy Programme, School of Rehabilitation Sciences, Faculty of Health Sciences, Universiti Kebangsaan Malaysia, Kuala Lumpur, Malaysia; ${ }^{5}$ Health Psychology Programme and Centre for Healthy Ageing and Wellness (H-CARE), Faculty of Health Sciences, Universiti Kebangsaan Malaysia, 50300 Kuala Lumpur, Malaysia; ' Internal Medicine \& Geriatric Department, Pusat Perubatan Universiti Kebangsaan Malaysia, Kuala Lumpur, Malaysia; ${ }^{7}$ Malaysian Research Institute on Ageing, Universiti Putra Malaysia, 43400 Serdang, Selangor, Malaysia
\end{abstract}

Correspondence: Suzana Shahar Dietetics Programme and Centre for Healthy Ageing and Wellness (H-CARE), Faculty of Health Sciences, Universiti Kebangsaan Malaysia, Jalan Raja Muda Abdul Aziz, Kuala Lumpur 50300, Malaysia Tel +60 392897 I59 7I63

Fax +60326938717

Email suzana.shahar@ukm.edu.my
Purpose: This study was aimed at determining the presence of cognitive frailty and its associated factors among community-dwelling older adults from the "LRGS-Towards Useful Aging (TUA)" longitudinal study.

Patients and methods: The available data related to cognitive frailty among a sub-sample of older adults aged 60 years and above $(n=815)$ from two states in Malaysia were analysed. In the LRGS-TUA study, a comprehensive interview-based questionnaire was administered to obtain the socio-demographic information of the participants, followed by assessments to examine the cognitive function, functional status, dietary intake, lifestyle, psychosocial status and biomarkers associated with cognitive frailty. The factors associated with cognitive frailty were assessed using a bivariate logistic regression (BLR).

Results: The majority of the older adults were categorized as robust $(68.4 \%)$, followed by cognitively pre-frail (37.4\%) and cognitively frail (2.2\%). The data on the cognitively frail and pre-frail groups were combined for comparison with the robust group. A hierarchical BLR indicated that advancing age $(\mathrm{OR}=1.04,95 \% \mathrm{CI}: 1.01-1.08, p<0.05)$ and depression $(\mathrm{OR}=1.49,95 \% \mathrm{CI}: 1.34-1.65, p<0.001)$ scored lower on the Activity of Daily Living (ADL) scale $(\mathrm{OR}=0.98,95 \% \mathrm{CI}: 0.96-0.99, p<0.05)$, while low social support $(\mathrm{OR}=0.98,95 \%$ $\mathrm{CI}: 0.97-0.99, p<0.05)$ and low niacin intake (OR=0.94, 95\% CI:0.89-0.99, $p<0.05$ ) were found to be significant factors for cognitive frailty. Higher oxidative stress (MDA) and lower telomerase activity were also associated with cognitive frailty $(p<0.05)$.

Conclusion: Older age, a lower niacin intake, lack of social support, depression and lower functional status were identified as significant factors associated with cognitive frailty among older Malaysian adults. MDA and telomerase activity can be used as potential biomarkers for the identification of cognitive frailty.

Keywords: frailty, mild cognitive impairment, cognitive frailty, older adults

\section{Introduction}

Frailty and cognitive decline have been identified as potent risk factors for dementia, functional decline, disability, poor quality of life, and mortality. ${ }^{1}$ Even though it has been shown that both frailty and cognitive impairment are related, ${ }^{2}$ these constructs were studied separately in most researches. ${ }^{3,4}$ To address this gap, a new construct called cognitive frailty was introduced by the International Academy on Nutrition and Aging (I.A.N.A) and the International Association of Gerontology and Geriatrics (I.A.G.G). ${ }^{5}$

Cognitive frailty has been described as a heterogeneous clinical manifestation characterized by the simultaneous presence of both physical frailty and cognitive 
impairment among older adults without dementia. ${ }^{5}$ Specifically, this concept may be useful in identifying individuals with cognitive impairment caused by physical and non-neurodegenerative conditions and to promote interventions that can lead to an improved quality of life among older adults.

Several population-based studies estimated the prevalence rate of cognitive frailty to be in the range of $1.0 \%$ to $12.0 \%,{ }^{6-8}$ whereas in clinical settings, the figure was much higher at $10.7 \%$ to $40 \% .^{9-11}$ Cognitive frailty can be influenced by a number of risk factors, including vascular, lifestyle, physical activity, smoking status, and psychosocial factors as well as potential effects of a poor nutritional status. $^{12}$ Moreover, although some emerging biomarkers are able to properly capture both the risk of future physical and cognitive decline individually, they may not be particularly specific for cognitive frailty. It is necessary to identify possible biomarkers that can serve better in determining the risks of cognitive frailty and can potentially be used as a molecular signature for targeted interventions. The aim of this study was to identify the presence of cognitive frailty and its comprehensive associated factors, including biomarkers, dietary intake, physical function and psychosocial status among multi-ethnic community-dwelling older adults in Malaysia.

\section{Materials and methods}

This was a cross-sectional study that used the previously reported methodology of the LRGS TUA study as its baseline. ${ }^{13}$ A sub-sample of 815 older adults from two states, namely Selangor and Perak, participated in this study, and the complete data on their physical and cognitive status was analysed. The data of 30 participants who matched the age and gender criteria were analysed for cognitive frailty biomarkers. The inclusion criteria were individuals aged 60 years and above with no documented major psychiatric illnesses or mental disorders. Participants with a Mini-Mental State Examination (MMSE) score of 14 and below (moderately severe or severe cognitive impairment) were excluded from this study. The study protocol was conducted in accordance with the Declaration of Helsinki and approved by the Medical Research and Ethics Committee of Universiti Kebangsaan Malaysia. The written informed consent of the participants and/or their relatives was obtained before enrolment.

The sampling for the study was done with the assistance of the Department of Statistics, Malaysia. Briefly, the participants were recruited using a multi-stage random sampling method from two states with the highest prevalence of older adults according to the zone, namely, Perak (North) and Selangor (Central). The sampling method for this study involved three stages; the primary sampling unit (PSU) was the selection of the state; the secondary sampling unit (SSU) was the random selection of 35 census circles (CCs) from each selected state; and the tertiary sampling unit (TSU) was the selection of 20 living quarters (LQs). The CCs were chosen with the older adults making up at least $10 \%$ of the total population in the selected CCs.

\section{Operationalization of cognitive frailty}

The classification of cognitive frailty was done based on the simultaneous presence of physical pre-frailty/frailty and subjective cognitive decline (SCC)/mild cognitive impairment (MCI), as summarized in Table 1.

The frailty assessment at the baseline was assessed based on the criteria used in the Cardiovascular Health Study. ${ }^{14}$ The presence of one or two criteria was defined as pre-frailty, and the presence of three or more criteria was defined as frailty. On the other hand, the classification of the cognitive status was carried out using pre-tested questionnaires and was based on a multi-dimensional domain that included physical functions, subjective and objective memory impairments, psycho-cognitive functioning, major diseases, health status, and quality of life. The participants were categorized as having MCI if they met the criteria by Petersen et al. ${ }^{15}$ (Table 1).

\section{Study instrument and data collection technique}

Face-to-face interviews were conducted with the participants using a standardized questionnaire, and measurements were made for a number of parameters. The questionnaire consisted of information on the socio-demography, neuropsychological and psychosocial functions, lifestyle and dietary intake of the participants. Other than that, the biophysical parameters, which included anthropometry, blood pressure, physical fitness, and functional status, were measured. The details of each protocol were previously published by Shahar et al. ${ }^{13}$ Since the measurements took quite some time to be completed, the participants were allowed to rest in between the data collection or tests, and refreshments and monetary incentives were provided. 
Table I Classification of robust, cognitive pre-frailty and cognitive frailty group

\begin{tabular}{|c|c|c|c|}
\hline & Robust & Cognitive Pre-Frailty & Cognitive Frailty \\
\hline \multirow[t]{2}{*}{ Frailty $^{14}$} & \multirow[t]{2}{*}{$\begin{array}{l}\text { Normal } \\
\text { physical } \\
\text { status }\end{array}$} & \multicolumn{2}{|c|}{$\begin{array}{l}\text { - Shrinking (subjective report of unintentional weight loss of } 5 \mathrm{~kg} \text { and above over the last year); } \\
\text { - Weakness (hand grip is less than the cut-off points mentioned on the original reference, adjusted for gender and } \\
\text { body mass index); } \\
\text { - Exhaustion and poor endurance and energy (indicating by self-reporting of exhaustion, identified by two questions } \\
\text { from the CES-D scale); } \\
\text { - Slowness (gait speed more than the cut-off points mentioned on the original reference, adjusted for gender and } \\
\text { height); } \\
\text { - Low physical activity, identified by low scores (in the lowest tertile) of the physical activity scale for elderly (PASE) }\end{array}$} \\
\hline & & Pre-frailty $=1-2$ criteria & Frailty $\geq 3$ criteria \\
\hline $\begin{array}{l}\text { Mild } \\
\text { Cognitive } \\
\text { Impairment }^{15}\end{array}$ & $\begin{array}{l}\text { No cogni- } \\
\text { tive impair- } \\
\text { ment }\end{array}$ & $\begin{array}{l}\text { - MMSE score }(\geq 19) \\
\text { - Self-report measure based on item } 10 \text { of the } 15 \text {-item } \\
\text { GDS } \\
\text { - Exclusion of concurrent AD dementia or other } \\
\text { dementias } \\
\text { - Objective memory impairment [poor performance in } \\
\text { one or more cognitive tests (Digit span and RAVLT) } \\
\text { with a score of at least I.5 SD below the mean } \\
\text { average] }\end{array}$ & $\begin{array}{l}\text { - } \text { MMSE score }(\geq 19) \\
\text { - Self-report measure based on item } 10 \text { of the } 15 \text {-item } \\
\text { GDS } \\
\text { - Exclusion of concurrent AD dementia or other } \\
\text { dementias } \\
\text { - Objective memory impairment [poor performance in } \\
\text { one or more cognitive tests (Digit span and RAVLT) } \\
\text { with a score of at least I.5 SD below the mean } \\
\text { average] }\end{array}$ \\
\hline
\end{tabular}

Abbreviation: RAVLT, Rey Auditory Verbal Learning Test.

\section{Socio-demography and health condition}

The socio-demography and health variables obtained included gender, age, education level, ethnicity, marital status, employment status, household income, smoking status, alcohol intake, and medical history.

\section{Nutritional status and clinical profile}

The nutritional status indicators included measurements of the weight, height, arm span, waist circumference, hip circumference, mid-upper arm circumference, and calf circumference as well as body composition [fat percentage $(\%)$, fat mass $(\mathrm{kg})$, free fat mass $(\mathrm{kg})$, and muscle mass $(\mathrm{kg})]$. Then, the Body Mass Index (BMI) was computed. The body circumference was measured using a non-extensible and flexible plastic measuring tape. The body composition was measured via the bio-impedance analysis (BIA) using the In Body S10 (Bio-space Co. Ltd, Korea). The systolic and diastolic blood pressures were also measured using a calibrated digital automatic blood pressure monitor (OMRON, Japan).

\section{Fitness and functional status}

A Senior Fitness Test (SFT) was used to measure physical fitness. ${ }^{16}$ A total of six fitness tests were administered, namely, the 2 min step, chair sit and reach, chair stand, time-up-and-go, back scratch and hand grip tests. ${ }^{16}$ The Activities of Daily Living (ADL) ${ }^{17}$ and Instrumental
Activities of Daily Living (IADL) ${ }^{18}$ were used to assess the functional status.

\section{Cognitive function test}

Among the cognitive function tests administered were the Digit Span Forward and Backward test for attention and working memory, ${ }^{19}$ the Rey Auditory Verbal Learning Test (RAVLT) for verbal memory, ${ }^{20}$ the Digit Symbol for information processing, the Visual Reproduction Test I \& II (VR I \& VR II) to assess visual memory, the Mini-Mental State Examination (MMSE), ${ }^{21}$ and the Montreal Cognitive Assessment (MoCA) for global functions.

\section{Psychosocial}

The Geriatric Depression Scale-15 (GDS) was used to assess potential depressive symptoms. ${ }^{22}$ Social support was assessed using the Medical Outcomes Study Social Support Survey (MOS-SS). ${ }^{23}$ Disability was measured using the 12-item version of WHODAS 2.0. ${ }^{24}$

\section{Dietary intake}

The dietary intake was obtained using a validated Dietary History Questionnaire (DHQ) and the nutrient intake was analysed using the Nutritionist Pro software. ${ }^{25}$ The output from the Nutritionist Pro was then exported into an Excel database. 


\section{Laboratory analysis}

A total of $20 \mathrm{~mL}$ of fasting peripheral venous blood was drawn by a phlebotomist using a butterfly syringe for the analysis of cognitive frailty biomarkers [superoxide dismutase (SOD), malonaldehyde (MDA), DNA damage (\% tail moment (TM) and tail density (TD)), vitamin D, brainderived neurotrophic factor (BDNF) and telomerase] and biochemical indices [fasting blood sugar, cholesterol, high-density lipoprotein (HDL), low-density lipoprotein (LDL) and triglycerides].

\section{Statistical analysis}

All the analyses were conducted using the IBM Statistical Package for Social Sciences (IBM SPSS), version 23.0 (SPSS Inc., Chicago, IL, USA). The statistical significance level was fixed at alpha $<0.05$ for all the tests. Descriptive and frequency analyses were executed for the prevalence of cognitive frailty. Comparisons of the sociodemographic factors, blood pressure, anthropometry, body composition, biochemical analysis, physical fitness tests, cognitive assessments, depression scale, psychosocial assessments, and dietary intake between the cognitively frail and robust groups were analysed using chi-squared $\left(\mathrm{Y}^{2}\right)$ tests for the categorical variables, and independent $t$-tests for the continuous variables. However, any independent variable that was used to define or score the cognitively frail group was excluded from the set of independent variables. The results were presented as $\mathrm{n}(\%)$ and the mean \pm standard deviation for normally distributed data.

A hierarchical binary logistic regression (BLR) was performed to determine the factors associated with cognitive frailty in a multivariate model. First, all the significant variables in the univariate analysis were categorized into 4 different groups according to (1) sociodemographic and medical status; (2) fitness, nutritional status, clinical profile, social support, functional and depression status; (3) dietary intake and; (4) biomarkers associated with cognitive frailty. Then, a hierarchical binary logistic regression was conducted for the four categories. Variables which appeared significant $(p<0.05)$ in each model were selected to be entered into the final binary logistic model. The significant variables in the final model were those factors that were associated with cognitive frailty among the study population.

\section{Results}

The majority of the participants were categorized as robust (68.4\%), followed by cognitively pre-frail $(37.4 \%)$, and cognitively frail $(2.2 \%)$. The data of the cognitively frail group were combined with those of the cognitively prefrail group (39.6\%) due to the lower prevalence of cognitive frailty as compared with the robust group (68.4\%). As shown in Table 2, the mean age of the participants was $68.86 \pm 6.12$ years old, with the majority of them being Chinese (50.9\%), followed by Malays (39.5\%), and Indians $(9.1 \%)$. The cognitively frail group had a significantly lower mean year of education and household income compared to the robust group $(p<0.05)$.

Table 3 shows that the blood pressure of the cognitively frail group was lower than that of the robust group, but only the diastolic blood pressure was significant $(p<0.05)$. With respect to the anthropometric measurements, the cognitively frail group had a lower mean value for the calf circumference. The fat-free mass and skeletal muscle mass were lower compared to those of the robust group $(p<0.05)$. The performance of the cognitively frail group, which was measured by means of physical fitness tests (2 min step, hand grip, chair stand, time up $\&$ go and back scratch) was lower than that of the robust group $(p<0.05)$. All the cognitive assessments (digit span, RAVLT, digit symbol, MoCA, VR I and VR II) in the cognitively frail group had significantly lower scores compared to the robust group $(p<0.05)$. Furthermore, the cognitively frail group had a significantly lower mean value for the psychosocial and physical function assessments (IADL and ADL) $(p<0.05)$. The mean value for WHODAS indicating disability and the Geriatric Scale for Depression (GDS-15) were significantly higher among the cognitively frail group compared to the robust group $(p<0.05)$. The cognitively frail group also had a significantly lower mean value for social support, as indicated by the MOSS scores $(p<0.05)$.

With respect to the dietary intake (Table 4), the energy and macronutrient (protein, carbohydrate, fat, and fibre) intakes appeared to be lower than those of the robust group, but were not significantly different. However, the nutrients, including riboflavin and niacin, had a significantly lower mean value among the cognitively frail group than the robust group $(p<0.05)$. An analysis of the randomly chosen age- and gendermatched subsamples for the biomarkers showed no significant difference in the SOD, Vitamin D and BDNF values among the older adults with cognitive frailty. In addition, the participants with cognitive frailty had a higher tendency of experiencing DNA damage with a higher percentage of TD as compared 
Table 2 Sociodemographic data associated with cognitive frailty [presented as $\mathrm{n}(\%)$ or mean \pm SD]

\begin{tabular}{|c|c|c|c|c|c|}
\hline & Parameter & Robust $(N=490)$ & Cognitive Frailty $(N=325)$ & Total $(\mathrm{N}=815)$ & $p$-value \\
\hline Age & $(M \pm S D)$ & $67.63 \pm 5.54$ & $69.44 \pm 6.23$ & $68.86 \pm 6.12$ & $<0.001^{\mathrm{a}}$ \\
\hline Gender & $\begin{array}{l}\text { Men } \\
\text { Women }\end{array}$ & $\begin{array}{l}234(36.3) \\
256(63.7)\end{array}$ & $\begin{array}{l}138(42.5) \\
187(57.5)\end{array}$ & $\begin{array}{l}372(45.6) \\
443(54.4)\end{array}$ & 0.151 \\
\hline Ethnic & $\begin{array}{l}\text { Malay \& Indian } \\
\text { Chinese }\end{array}$ & $\begin{array}{l}265(54.1) \\
225(45.9)\end{array}$ & $\begin{array}{l}135(41.5) \\
190(58.5)\end{array}$ & $\begin{array}{l}400(49.1) \\
415(50.9)\end{array}$ & $<0.001^{\mathrm{a}}$ \\
\hline Years of education & $\begin{array}{l}\leq 6 \text { years } \\
>6 \text { years }\end{array}$ & $\begin{array}{l}293(59.8) \\
197(40.2)\end{array}$ & $\begin{array}{l}234(72.0) \\
91(28.0)\end{array}$ & $\begin{array}{l}527(64.7) \\
288(35.3)\end{array}$ & $<0.001^{\mathrm{a}}$ \\
\hline Occupation & $\begin{array}{l}\text { Not working } \\
\text { Working }\end{array}$ & $\begin{array}{l}395(88.2) \\
53(11.8)\end{array}$ & $\begin{array}{l}265(86.9) \\
40(13.1)\end{array}$ & $\begin{array}{l}660(87.6) \\
93(12.4)\end{array}$ & 0.652 \\
\hline $\begin{array}{l}\text { Household } \\
\text { income }\end{array}$ & $\begin{array}{l}\text { Low income (SRMI500) } \\
\text { High income (>RMI500) }\end{array}$ & $\begin{array}{l}317(65.8) \\
165(34.2)\end{array}$ & $\begin{array}{l}239(74.2) \\
83(25.8)\end{array}$ & $\begin{array}{l}556(69.2) \\
248(30.8)\end{array}$ & $0.013^{\mathrm{a}}$ \\
\hline Marriage status & $\begin{array}{l}\text { Single/widow/widower/divorced } \\
\text { Married }\end{array}$ & $\begin{array}{l}136(27.8) \\
354(72.2)\end{array}$ & $\begin{array}{l}89(27.4) \\
236(72.6)\end{array}$ & $\begin{array}{l}225(27.6) \\
590(72.4)\end{array}$ & 0.936 \\
\hline Smoking status & $\begin{array}{l}\text { Past or non-smokers } \\
\text { Smoking }\end{array}$ & $\begin{array}{l}58(11.8) \\
432(88.2)\end{array}$ & $\begin{array}{l}42(12.9) \\
283(87.1)\end{array}$ & $\begin{array}{l}100(12.3) \\
715(87.7)\end{array}$ & 0.664 \\
\hline $\begin{array}{l}\text { Medical profile } \\
\text { Hypertension }\end{array}$ & $\begin{array}{l}\text { Yes } \\
\text { No }\end{array}$ & $\begin{array}{l}435(53.4) \\
380(46.6)\end{array}$ & $\begin{array}{l}260(53.1) \\
230(46.9)\end{array}$ & $\begin{array}{l}175(53.8) \\
150(39.5)\end{array}$ & 0.830 \\
\hline Dyslipidaemia & $\begin{array}{l}\text { Yes } \\
\text { No }\end{array}$ & $\begin{array}{l}283(34.7) \\
532(65.3)\end{array}$ & $\begin{array}{l}160(32.7) \\
330(67.3)\end{array}$ & $\begin{array}{l}123(37.8) \\
202(62.2)\end{array}$ & 0.133 \\
\hline Diabetes Mellitus & $\begin{array}{l}\text { Yes } \\
\text { No }\end{array}$ & $\begin{array}{l}242(29.7) \\
573(70.3)\end{array}$ & $\begin{array}{l}142(29) \\
348(7 I)\end{array}$ & $\begin{array}{l}100(30.8) \\
225(69.2)\end{array}$ & 0.585 \\
\hline Heart disease & $\begin{array}{l}\text { Yes } \\
\text { No }\end{array}$ & $\begin{array}{l}79(9.7) \\
736(90.3)\end{array}$ & $\begin{array}{l}42(8.6) \\
448(91.4)\end{array}$ & $\begin{array}{l}37(11.4) \\
288(88.6)\end{array}$ & 0.186 \\
\hline
\end{tabular}

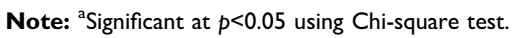

to the robust participants, but there was no significant difference. However, the MDA level was significantly higher in the cognitively frail group while the telomerase level was lower compared to the robust group for the biomarker parameters $(p<0.05)$ (Table 5$)$.

The final model was indicated by the results of the hierarchical logistic regression, where advancing age $(\mathrm{OR}=1.04, \quad 95 \% \quad \mathrm{CI}: 1.01-1.08, \quad p<0.05), \quad$ depression (OR1.49, 95\% CI:1.34-1.65, $p<0.001$ ), low functional status as indicated by the ADL (OR $=0.98,95 \%$ CI:0.96- 0.99 , $p<0.05$ ), low social support ( $\mathrm{OR}=0.98,95 \%$ CI:0.97-0.99, $p<0.05$ ), and low niacin intake ( $\mathrm{OR}=0.94,95 \% \mathrm{CI}: 0.89$ $0.99, p<0.05)$ were found to be significant factors associated with the cognitively frail group (Table 6).

\section{Discussion}

In the present study, the prevalence rate of cognitive frailty among the multi-ethnic older population in Malaysia was
$2.2 \%$, and this was comparable with the findings from among the Japanese $(2.7 \%)$ and Italian $(2.5 \%)$ population. ${ }^{2,7}$ A higher prevalence rate $(39.6 \%)$ was shown when both the cognitively pre-frail and cognitively frail were combined into a single group. The Singapore Longitudinal Ageing Studies (SLAS) also combined the cognitively frail and cognitively pre-frail categories and obtained a prevalence rate of $10.7 \%$ among Chinese population, ${ }^{6}$ which was lower than the figure reported in the present study. The discrepancy in the prevalence rates may be due to the number of older participants in the present study and the difference in the study population. Pre-frailty is clearly different from normal aging, based on the clinical, functional and behavioural factors and biomarkers involved in the pathological aging process, ${ }^{26}$ hence, suggesting that it can be grouped together with frailty to be considered as a target group for possible interventions.

This study found that every increase of one year in age is associated with increasing odds of the incidence of 
Table 3 Fitness, cognitive assessments, nutritional status, clinical profile, functional status and depression status of the subjects [presented as $\mathrm{n}(\%)$ or mean $\pm \mathrm{SD}$ ]

\begin{tabular}{|c|c|c|c|c|}
\hline Parameters & Robust (N=490) & $\begin{array}{l}\text { Cognitive Frailty } \\
(\mathrm{N}=325)\end{array}$ & Total $(\mathrm{N}=8 \mid \mathbf{5})$ & $p$-value \\
\hline \multicolumn{5}{|l|}{ Anthropometry } \\
\hline \multicolumn{5}{|l|}{ Body mass index $\left(\mathrm{kg} / \mathrm{m}^{2}\right)$} \\
\hline Underweight & $12(2.5)$ & $13(4.0)$ & $25(3.1)$ & 0.357 \\
\hline Normal & $229(46.8)$ & $149(45.8)$ & $378(46.4)$ & \\
\hline Overweight & $182(37.2)$ & $110(33.8)$ & $292(35.9)$ & \\
\hline Obese & $66(13.5)$ & $53(16.3)$ & $119(14.6)$ & \\
\hline Waist circumference $(\mathrm{cm})$ & $89.86 \pm 10.91$ & $88.89 \pm 11.19$ & $89.50 \pm \mid 1.31$ & 0.222 \\
\hline Hip circumference $(\mathrm{cm})$ & $98.48 \pm \mid 0.91$ & $97.78 \pm 9.44$ & $98.17 \pm 9.29$ & 0.337 \\
\hline Mid-upper arm circumference $(\mathrm{cm})$ & $28.98 \pm 3.18$ & $28.62 \pm 3.42$ & $28.87 \pm 3.44$ & 0.126 \\
\hline Calf circumference $(\mathrm{cm})$ & $34.37 \pm 3.63$ & $33.8 I \pm 3.64$ & $34.01 \pm 3.65$ & $0.034^{\mathrm{a}}$ \\
\hline \multicolumn{5}{|l|}{ Body composition } \\
\hline Fat (\%) & $38.54 \pm 10.19$ & $38.68 \pm 10.25$ & $38.61 \pm 10.42$ & 0.840 \\
\hline Fat mass $(\mathrm{kg})$ & $24.81 \pm 8.82$ & $24.22 \pm 9.45$ & $24.52 \pm 9.29$ & 0.377 \\
\hline Fat-free mass (kg) & $38.66 \pm 8.3$ & $37.07 \pm 7.59$ & $37.37 \pm 8.09$ & $0.006^{\mathrm{a}}$ \\
\hline Skeletal muscle mass $(\mathrm{kg})$ & $20.66 \pm 5.00$ & $19.70 \pm 4.53$ & $19.88 \pm 4.83$ & $0.006^{\mathrm{a}}$ \\
\hline \multicolumn{5}{|l|}{ Clinical profile } \\
\hline Systolic blood pressure $(\mathrm{mmHg})$ & $|39.48 \pm 20.7|$ & $138.69 \pm 20.40$ & $\mid 39.83 \pm 21.01$ & 0.597 \\
\hline Diastolic blood pressure $(\mathrm{mmHg})$ & $77.59 \pm 12.75$ & $75.56 \pm 12.96$ & $76.92 \pm 13.02$ & $0.030^{\mathrm{a}}$ \\
\hline \multicolumn{5}{|l|}{ Fitness } \\
\hline 2-min step test & $68.17 \pm 25.85$ & $63.68 \pm 26.00$ & $65.21 \pm 26.13$ & $0.016^{\mathrm{a}}$ \\
\hline Chair stand test & $10.56 \pm 2.91$ & $9.80 \pm 3.29$ & $10.09 \pm 3.06$ & $0.001^{\mathrm{a}}$ \\
\hline Time-up and go & $10.11 \pm 2.85$ & $10.72 \pm 3.29$ & $10.69 \pm 3.09$ & $0.005^{\mathrm{a}}$ \\
\hline Chair sit and reach & $3.33 \pm 10.22$ & $4.63 \pm 4.64$ & $4.38 \pm 11.40$ & 0.086 \\
\hline Back scratch test & $13.83 \pm 12.52$ & $17.36 \pm 14.58$ & $16.43 \pm 13.83$ & $<0.001^{a}$ \\
\hline \multicolumn{5}{|l|}{ Depression } \\
\hline No depressive symptoms & $434(88.6)$ & $240(73.8)$ & $674(82.7)$ & $<0.001^{\mathrm{a}}$ \\
\hline Depressive symptoms & $56(\mathrm{I} I .4)$ & $85(26.2)$ & I4I (I7.3) & \\
\hline \multicolumn{5}{|l|}{ Cognitive assessments } \\
\hline Digit symbol & $6.18 \pm 3.12$ & $5.53 \pm 2.77$ & $5.59 \pm 2.84$ & $0.003^{\mathrm{a}}$ \\
\hline Digit span & $7.92 \pm 2.50$ & $8.09 \pm 2.61$ & $7.8 I \pm 2.53$ & 0.349 \\
\hline RAVLT & $39.10 \pm 10.88$ & $38.97 \pm 10.11$ & $38.32 \pm 10.59$ & $0.87 I$ \\
\hline $\mathrm{MoCA}$ & $20.45 \pm 5.46$ & $19.53 \pm 5.42$ & $19.59 \pm 5.57$ & $0.018^{a}$ \\
\hline VR I & $53.43 \pm 33.16$ & $48.42 \pm 32.87$ & $49.15 \pm 32.82$ & $0.036^{\mathrm{a}}$ \\
\hline VR II & $45.63 \pm 36.85$ & $39.50 \pm 36.05$ & $40.00 \pm 35.94$ & $0.020^{\mathrm{a}}$ \\
\hline \multicolumn{5}{|l|}{ Functional status } \\
\hline IADL & $13.15 \pm 1.47$ & $12.83 \pm 1.92$ & $12.80 \pm 1.98$ & $0.004^{\mathrm{a}}$ \\
\hline ADL & $41.50 \pm 9.58$ & $37.88 \pm 10.24$ & $38.81 \pm 10.41$ & $<0.001^{\mathrm{a}}$ \\
\hline WHODAS & $5.28 \pm 8.42$ & $6.86 \pm 9.27$ & $6.67 \pm 9.50$ & $0.013^{\mathrm{a}}$ \\
\hline Social support & $39.92 \pm 14.18$ & $35.77 \pm 15.05$ & $39.32 \pm 14.49$ & $<0.001^{\mathrm{a}}$ \\
\hline
\end{tabular}

Note: ${ }^{a}$ Significant at $p<0.05$ using Independent $t$-test.

Abbreviations: RAVLT, Rey Auditory Verbal Learning Test; MoCA, Montreal Cognitive Assessment; VR I, Visual Reproduction I; VR II, Visual Reproduction II; IADL, Instrumental Activity of Daily Living; ADL, Activity of Daily Living.

cognitive frailty among older Malaysian adults. Advancing age has consistently been reported as a major risk factor for both physical frailty and cognitive impairment. ${ }^{1,27}$ In addition, the presence of multiple subclinical and age- related comorbidities in older adults may exacerbate the decline in several physiological systems, resulting in homeostatic imbalance or frailty, ${ }^{28}$ brain aging and consequently, cognitive decline. ${ }^{1}$ Besides, aging is associated 
Table 4 Dietary intake of subjects (presented as Mean \pm SD)

\begin{tabular}{|c|c|c|c|c|}
\hline Nutrients & Robust $(\mathrm{N}=490)$ & $\begin{array}{l}\text { Cognitive Prefrailty/Frailty } \\
(\mathrm{N}=325)\end{array}$ & Total & $p$-value \\
\hline Energy (kcal) & $1655 \pm 445$ & $1612 \pm 436$ & $1659 \pm 453$ & 0.184 \\
\hline Protein $(g / k g)$ & $1.15 \pm 0.38$ & $1.13 \pm 0.42$ & $|| 4 \pm 0.4 \mid$. & 0.771 \\
\hline Carbohydrate (\%) & $53.37 \pm 7.96$ & $53.05 \pm 7.66$ & $53.70 \pm 7.96$ & 0.564 \\
\hline Fat $(\%)$ & $29.62 \pm 7.96$ & $29.79 \pm 6.40$ & $29.42 \pm 7.20$ & 0.749 \\
\hline Vit A ( $\mu g$ RE) & $400.5 \pm 296.24$ & $420.40 \pm 308.48$ & $393.01 \pm 286.40$ & 0.374 \\
\hline Vit C (mg) & $127.87 \pm 83.27$ & $|26.54 \pm 80.2|$ & $122.12 \pm 84.30$ & 0.826 \\
\hline Vit D $(\mu \mathrm{g})$ & $0.36 \pm 0.84$ & $0.39 \pm 1.32$ & $0.33 \pm 1.00$ & 0.725 \\
\hline Vit E (mg) & $7.30 \pm 40.66$ & $6.54 \pm \mid 8.01$ & $9.15 \pm 44.81$ & 0.725 \\
\hline Riboflavin (mg) & $1.29 \pm 0.52$ & I. $19 \pm 0.47$ & $1.23 \pm 0.50$ & $0.005^{\mathrm{a}}$ \\
\hline Niacin (mg) & $10.34 \pm 3.95$ & $9.45 \pm 3.21$ & $9.91 \pm 3.76$ & $0.00 \mathrm{I}^{\mathrm{a}}$ \\
\hline Calcium (mg) & $510.39 \pm 227.7 \mid$ & $522.19 \pm 260.76$ & $508.99 \pm 241.54$ & 0.508 \\
\hline Iron (mg) & $13.72 \pm 5.34$ & $13.35 \pm 5.06$ & $13.49 \pm 5.27$ & 0.323 \\
\hline Zinc (mg) & $3.66 \pm 1.87$ & $3.57 \pm 1.74$ & $3.56 \pm 1.86$ & 0.502 \\
\hline
\end{tabular}

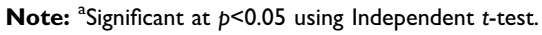

Table 5 Biomarkers associated to cognitive frailty (presented as mean \pm SD)

\begin{tabular}{|l|l|l|l|l|l|}
\hline \multirow{2}{*}{ Analysis } & \multicolumn{2}{l|}{ Status (M \pm SD) } & \multirow{2}{*}{ F } & \multirow{2}{*}{ t } \\
\cline { 2 - 5 } & Robust & Cognitive Prefrailty/Frailty & \\
\hline SOD (u.e/min/mg protein) & $9.36 \pm 7.30$ & $9.39 \pm 9.11$ & 0.546 & -0.009 \\
MDA (nmol/L) & $1.97 \pm 0.75$ & $2.71 \pm 0.66$ & 0.184 & -2.469 & 0.993 \\
DNA in tail (\%) & $12.37 \pm 4.68$ & $14.02 \pm 4.97$ & 0.274 & -0.783 & $0.020^{\mathrm{a}}$ \\
Tail Moment (\%) & $1.61 \pm 0.67$ & $1.59 \pm 0.55$ & 0.752 & 0.086 & 0.933 \\
Vitamin D (nmol/L) & $49.73 \pm 18.33$ & $52.27 \pm 7.65$ & 2.167 & -0.369 & 0.721 \\
BDNF (nmol/L) & $13.80 \pm 1.75$ & $12.85 \pm 2.17$ & 0.590 & 0.956 & 0.354 \\
Telomerase (nmol/L) & $7.16 \pm 1.25$ & $5.76 \pm 0.90$ & 2.315 & 2.577 \\
\hline
\end{tabular}

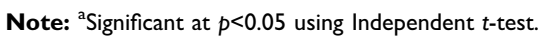

Abbreviation: MDA, malonaldehyde.

Table 6 Factors associated to cognitive frailty

\begin{tabular}{|l|l|l|l|l|}
\hline Parameters & B & Standard error & OR (95\% Cl) & p-value \\
\hline Age & 0.038 & 0.18 & $1.04(1.01-1.08)$ & $0.030^{\mathrm{a}}$ \\
\hline $\begin{array}{l}\text { GDS category } \\
\text { No depressive symptoms } \\
\text { Depressive symptoms }\end{array}$ & 0.397 & 0.05 & $1.49(1.34-1.65)$ & $<0.00 I^{\mathrm{a}}$ \\
\hline ADL & -0.024 & 0.01 & $0.98(0.96-0.99)$ & $0.028^{\mathrm{a}}$ \\
\hline Social support & -0.021 & 0.01 & $0.98(0.97-0.99)$ & $0.00 I^{\mathrm{a}}$ \\
\hline Niacin (mg) & -0.066 & 0.03 & $0.94(0.89-0.99)$ & $0.030^{\mathrm{a}}$ \\
\hline
\end{tabular}

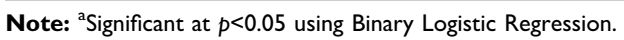

Abbreviations: GDS, Geriatric Depression Scale-I5; ADL, Activities of Daily Living.

with inadequate social integration and social support that may lead to a decline in physical and mental functions. ${ }^{29}$

The lack of social support was apparent among the cognitively frail subjects, where a decrease of 1 unit in the MOSS scores increased the risk of cognitive frailty by $2 \%$.
Social support, in terms of providing assistance and encouragement to older adults, is a protective function against frailty and cognitive dysfunction. ${ }^{30,31}$ Social support among older adults has a proximal relationship with depression, ${ }^{32,33}$ which appeared to be higher among the 
cognitively frail participants. Depression is often accompanied by neurocognitive deficits and physical frailty, whereby it is associated with greater disability and an increased risk of dementia. ${ }^{34,35}$ A persistent depressive mood, anxiety, impatience, and behavioural suppression may also reduce an individual's desire to participate in social activities, and impede access to a necessary social support system, thereby resulting in an increased risk of disabilities among older adults. ${ }^{36}$ Disability, as indicated by the lower ADL scores, was indicated among the cognitively frail subjects, where a reduction of 1 point increased the risk of cognitive frailty by $2 \%$. In line with this finding, ADL impairment has been reported to be a predictive factor of future cognitive impairment ${ }^{37}$ and physical frailty. ${ }^{38}$

With respect to dietary intake, this study found that lowering the intake of niacin by $1 \mathrm{mg}$ would increase the risk of the incidence of cognitive frailty by $6 \%$, and the niacin intake of the participants did not even meet the recommendation for older adults ( $16 \mathrm{mg} /$ day $).{ }^{39}$ Niacin deficiency will lead to the occurrence of pellagra, whereby a patient can develop neurological deficits manifesting as dementia. ${ }^{40}$ Several studies have proposed that niacin has a therapeutic effect on depression, ${ }^{41,42}$ which often accompanies physical frailty and cognitive impairment. ${ }^{34}$ This suggests that niacin may be a potential biomarker and predictor for cognitive frailty among older adults.

In a subsample analysis, the age- and gender-matched cognitively frail participants showed a higher level of oxidative stress, as indicated by their MDA levels, compared to the robust participants. Ingles et al. ${ }^{43}$ reported that frail older adults displayed more oxidative damage than the non-frail participants. Moreover, several studies have reported the contribution of high plasma MDA levels in the neurodegenerative process of dementia. ${ }^{44,45}$ Oxidative stress may also increase the rate of telomere shortening by site-specific DNA damage to the telomere sequence. ${ }^{46}$ Besides, the telomerase level was found to be lower among the cognitively pre-frail/frail participants in the present study, and this may have reduced their ability to repair the damage done to the DNA, whereby the percentage of TM was higher among the cognitively frail participants. The presence of functional telomerase is a necessary condition for maintaining the telomere length, hence, preserving healthy cell and long-term immune functions. ${ }^{47}$ Even though no study has been done on the direct interaction between telomerase activity and cognitive frailty, telomere shortening is associated with both physical frailty and cognitive decline. ${ }^{48-50}$ In line with this, the contribution of telomere shortening to persistent DNA damage response during replicative senescence, and the irreversible loss of the division potential of somatic cells have been reported. ${ }^{51}$ Hence, the presence of oxidative stress and the absence of telomerase activity in preserving the telomere length may be one of the factors for determining the development of cognitive frailty among older adults, and further research involving a larger sample size is needed.

This study had several limitations. Although the participants were selected randomly, the sample did not represent all the ethnic groups in the Malaysian community. The majority of the participants who were recruited from two out of the 14 states in Malaysia were Chinese, whilst the Malays are the major ethnic group in the Malaysian community. The two selected states may also not be representative of the other 12 states, particularly those in East Malaysia. Furthermore, this study could not elucidate the predictive validity of the risk factors due to its crosssectional design. Hence, a longitudinal study should be carried out to determine the ability of cognitive frailty to predict dementia. However, the findings of this study provided substantial insights into the prevalence of cognitive frailty among older Malaysian adults, and identified several factors associated with cognitive frailty.

\section{Conclusion}

In conclusion, the prevalence of robust, cognitive prefrailty and cognitive frailty among older adults in Malaysia was $60.4 \%, 37.4 \%$, and $2.2 \%$, respectively. Being older, having a low niacin intake, depression, low functional status and lack of social support were associated with cognitive frailty among older Malaysian adults. The results of this study also suggest that MDA and telomerase can be used as potential biological markers for the identification of cognitive frailty. Future studies are warranted to further investigate the prevalence and risk factors of cognitive frailty among the entire Malaysian population, and to develop simple screening tools to identify cognitive frailty among older adults. This study can also be a stepping stone for future researchers to develop prevention and intervention strategies against cognitive frailty.

\section{Acknowledgments}

The authors would like to acknowledge the financial support under the Long-term Research Grant Scheme (LRGS) provided by Ministry of Education Malaysia (LRGS/BU/ 2012/UKM-UKM/K/01) and Grand Challenge Grant 
funded by National University of Malaysia (DCP-2017002/1). The authors would like to express utmost gratitude to all the field workers, staffs, local authorities, coresearchers and participants for their involvement in this study.

\section{Disclosure}

The authors report no conflicts of interest in this work.

\section{References}

1. Robertson DA, Savva GM, Anne R. Frailty and cognitive impairment - a review of the evidence and causal mechanisms. Ageing Res Rev. 2013;12(4):840-851. doi:10.1016/j.arr.2013.06.004

2. Shimada H, Makizako H, Doi T, et al. Combined prevalence of frailty and mild cognitive impairment in a population of elderly Japanese people. J Am Med Dir Assoc. 2013;14(7):518-524. doi:10.1016/j. jamda.2013.03.010

3. Badrasawi M, Shahar S, Kaur D, Singh A. Risk factors of frailty among multi-ethnic Malaysian older adults. Int J Gerontol. 2017;11 (3):154-160. doi:10.1016/j.ijge.2016.07.006

4. Eshkoor SA, Hamid A, Shahar S, Mun CY Peertechz. Research predictive factors of severe stage of dementia among the Malaysian elderly. J Nutr Gerontol Geriatr. 2016;1:6-12.

5. Kelaiditi E, Cesari M, Canevelli M, et al. Cognitive frailty : rational and definition from an (I .A.N.A./I.A.G.G.) international consensus group. $J$ Nutr Health Aging. 2013;17:9. doi:10.1007/s12603-013-0367-2

6. Feng L, Shwe M, Nyunt Z, et al. Physical frailty, cognitive impairment, and the risk of neurocognitive disorder in the Singapore longitudinal ageing studies. $J$ Gerontol. 2017;72(3):369-375. doi:10.1093/gerona/glw050

7. Solfrizzi V, Scafato E, Seripa D, et al. Reversible cognitive frailty, dementia, and all-cause mortality. The Italian longitudinal study on aging. $J$ Am Med Dir Assoc. 2017;18:1-8. doi:10.1016/j. jamda.2016.10.012

8. John PDS, Tyas SL, Griffith LE, Menec V. The cumulative effect of frailty and cognition on mortality - results of a prospective cohort study. Int Psychogeriatr. 2016;29(4):535-543. doi:10.1017/ S1041610216002088

9. Montero-odasso MM, Barnes B, Speechley M, et al. Disentangling cognitive-frailty : results from the gait and brain study. J Gerontol Ser A. 2016;71(11):1476-1482. doi:10.1093/gerona/glw044

10. Delrieu J, Andrieu S, Pahor M, et al. Neuropsychological profile of "cognitive frailty" subjects in MAPT study. J Prev Alzheimers Dis. 2016;3(3):151-159. doi:10.14283/jpad.2016.94.Neuropsychological

11. Jha SR, Hannu MK, Gore K, et al. Cognitive impairment improves the predictive validity of physical frailty for mortality in patients with advanced heart failure referred for heart transplantation. J Hear Lung Transplant. 2016;35(9):1092-1100. doi:10.1016/j.healun.2016.04.008

12. Fougère B, Daumas M, Lilamand M, Sourdet S, Delrieu J, Vellas B. Association between frailty and cognitive impairment : cross-sectional data from toulouse frailty day hospital. J Am Med Dir Assoc. 2017;1-5. doi:10.1016/j.jamda.2017.06.024

13. Shahar S, Omar A, Vanoh D, Aizan T. Approaches in methodology for population-based longitudinal study on neuroprotective model for healthy longevity (TUA) among Malaysian older adults. Aging Clin Exp Res. 2015. doi:10.1007/s40520-0150511-4

14. Fried LP, Tangen CM, Walston J, et al. Frailty in older adults : evidence for a phenotype. J Gerontol Ser A. 2001;56(3):146-157. doi:10.1093/gerona/56.3.M146
15. Petersen RC, Caracciolo B, Brayne C, Gauthier S, Jelic V, Fratiglioni L. Mild cognitive impairment : a concept in evolution. J Intern Med. 2014;275(3):214-228. doi:10.1111/joim. 12190

16. Jones CJ, Rikli RE. Measuring functional. J Act Aging. 2002; April:24-30.

17. Katz S, Ford AB, Moskowitz RW, Jackson BA, Jaffe MW. Index of independence in activities of daily living (Katz Index of ADL) studies of illness in the aged. The index of ADL: a standardized measure of biological and psychosocial function. JAMA. 1963;185 (12):914-919.

18. Fillenbaum GG. Screening the elderly: a brief instrumental activities of daily living measure. J Am Geriatr Soc. 1985;33(10):698-706.

19. Wechsler D. Wechsler Adult Intelligence Scale-III. San Antonio: The Psychological Corporation; 1997.

20. Strauss E, Sherman EM, Spreen O. A Compendium of Neuropsychological Tests: Administration, Norms, and Commentary. New York: Oxford University Press; 2006.

21. Folstein MF, Folstein SE, McHugh PR. "Mini-mental state": a practical method for grading the cognitive state of patients for the clinician. J Psychiatr Res. 1975;12(3):189-198.

22. Yesavage JA, Sheikh JI. Geriatric depression scale: recent evidence and development of a shorter version. Clin Gerontol. 1986. doi:10.1300/J018v05n01

23. Sherbourne CD, Stewart AL. The MOS social support survey. Soc Sci Med. 1991;32(6):705-714. doi:10.1016/0277-9536(91) 90150-B

24. Andrews G, Kemp A, Sunderland M, Von Korff M, Ustun TB. Normative data for the 12 item who disability assessment schedule 2.0. PLoS One. 2009;4(12):1-6. doi:10.1371/journal. pone.0008343

25. Shahar S, Earland J, Rahman SA. Validation of a dietary history questionnaire against a 7-D weighed record for estimating nutrient intake among rural elderly malays. Malays J Nutr. 2000;6(1):33-44.

26. Van Kan GA, Rolland YM, Morley JE, Vellas B. Frailty : toward a Clinical Definition. Editorials. 2007;71-72. doi:10.1016/j. jamda.2007.11.005

27. Fulop T, Larbi A, Witkowski JM, et al. Aging, frailty and age-related diseases. Biogerontology. 2010:547-563. doi:10.1007/s10522-0109287-2

28. Clegg A, Young J, Iliff S, Rikkert MO, Rockwood K. Frailty in elderly people. The Lancet. 2013;381(9868):752-762. doi:10.1016/ S0140-6736(12)62167-9

29. Ibrahim N, Che N, Ma D, Ahmad M. Relationships between social support and depression, and quality of life of the elderly in a rural community in Malaysia. Asia-Pacific Psychiatry. 2013;5:59-66. doi:10.1111/appy. 12068

30. Etman A, Kamphuis CBM, Van Der Cammen TJM, Burdorf A, Van Lenthe FJ. Do lifestyle, health and social participation mediate educational inequalities in frailty worsening? Eur J Public Health. 2014;25:345-350. doi:10.1093/eurpub/cku093

31. Yilmaz FT, Aldemir K, Kumsar AK. Does social support affect development of cognitive dysfunction in individuals with diabetes mellitus? Saudi Med J. 2015;36(12):1425-1431. doi:10.15537/ smj.2015.12.12845

32. Olutoki MO, Olagunju AT, Adeyemi JD. Aging \& mental health correlates of depressive illness among the elderly in a mixed urban community in Lagos, Nigeria. Aging Ment Health. 2014;18:561-569. doi:10.1080/13607863.2013.843156

33. Toyin A, Olasunkanmi M, Peter O, Dada J. Late-life depression: burden, severity and relationship with social support dimensions in a West African community. Arch Gerontol Geriatr. 2015;61(2):240 246. doi:10.1016/j.archger.2015.05.002

34. Arts MHL, Collard RM, Comijs HC, et al. Physical frailty and cognitive functioning in depressed older adults : findings from the NESDO Study. J Am Med Dir Assoc. 2015. doi:10.1016/j. jamda.2015.07.016 
35. Potter GG, Mcquoid DR, Whitson HE, Steffens DC, Sciences B. Physical frailty in late-life depression is associated with deficits in speed-dependent executive functions. Int $J$ Geriatr Psychiatry. 2017;31(5):466-474. doi:10.1002/gps.4351.Physical

36. Kazama M, Kondo N, Suzuki K, Minai J, Imai H, Yamagata Z. Early impact of depression symptoms on the decline in activities of daily living among older Japanese : Y-HALE cohort study. Environ Health Prev Med. 2011;16(3):196-201. doi:10.1007/s12199-010-0186-6

37. Fauth EB, Schwartz S, Tschanz JT, Corcoran C, Norton MC. Baseline disability in activities of daily living predicts dementia risk even after controlling for baseline global cognitive ability and depressive symptoms. Int J Geriatr Psychiatry. 2012;28(6):597-606. doi:10.1002/ gps.3865

38. Al Snih S, Graham JE, Ray LA, Samper R, Markides KS, Ottenbacher KJ. Frailty and incidence of activities of daily living. $J$ Rehabil Med. 2009;41(11):892-897. doi:10.2340/16501977-0424. FRAILTY

39. Recommended Nutrient Intake. A Report of the Technical Working Group on Nutritional Guidelines. Ministry of Health Malaysia. 2017.

40. Fricker RA, Green EL, Jenkins SI, Griffin SM. The influence of nicotinamide on health and disease in the central nervous system. Int J Tryptophan Res. 2018;11. doi:10.1177/1178646918776658

41. Prousky JE. Vitamin B3 for depression : case report and review of the literature. J Orthomol Med. 2016;25(3):137-147.

42. Ishizaki J, Yamamoto H, Takahashi T, Takeda M, Yano M, Mimura M. Changes in regional cerebral blood flow following antidepressant treatment in late-life depression. Int J Geriatr Psychiatry. 2008;23 (8):805-811. doi:10.1002/gps
43. Ingles M, Gambini J, Carnicero JA, et al. Oxidative stress is related to frailty, not to age or sex, in a geriatric population : lipid and protein oxidation as biomarkers of frailty. J Am Geriatr Soc. 2014;62 (7):1324-1328. doi:10.1111/jgs.12876

44. Meramat A, Rajab NF, Shahar S, Sharif RA. DNA damage, copper and lead associates with cognitive function among older adults. $J$ Nutr Health Aging. 2016;21(5):539-545. doi:10.1007/s12603-0160759-1

45. Abizanda Soler P, Lopez-Torres Hidalgo J, Romero Rizos L, et al. [Frailty and dependence in Albacete (FRADEA study): reasoning, design and methodology]. Rev Esp Geriatr Gerontol. 2011;46(2):8188. doi:10.1016/j.regg.2010.10.004

46. Ahmed W, Lingner J. Impact of oxidative stress on telomere biology. Differentiation. 2018;99:21-27. doi:10.1016/j.diff.2017.12.002

47. Blackburn EH. Telomere states and cell fates. Nature. 2000;408 (6808):53-56. doi:10.1038/35040500

48. Martinez-Ezquerro JD, Rodriguez-Castaneda A, Ortiz-Ramirez M, et al. Association of oxidative stress, telomere length, and frailty in an elder population. bioRxiv. 2018;1-15. doi:10.1101/414680

49. Lau H, Fitri A, Ludin M, Rajab NF, Shahar S. Identification of neuroprotective factors associated with successful ageing and risk of cognitive impairment among Malaysia older adults. Malays $J$ Health Sci. 2017;15(2):97-102.

50. Roberts RO, Boardman LA, Cha RH, et al. Short and long telomeres increase risk of amnestic mild cognitive impairment. Mech Ageing Dev. 2014;141-142:64-69. doi:10.1016/j.mad.2014.10.002

51. Hewitt G, Jurk D, Marques FDM, et al. DNA damage response in ageing and. Nat Commun. 2012;3:708. doi:10.1038/ncomms1708
Clinical Interventions in Aging

\section{Publish your work in this journal}

Clinical Interventions in Aging is an international, peer-reviewed journal focusing on evidence-based reports on the value or lack thereof of treatments intended to prevent or delay the onset of maladaptive correlates of aging in human beings. This journal is indexed on PubMed Central, MedLine, CAS, Scopus and the Elsevier
Bibliographic databases. The manuscript management system is completely online and includes a very quick and fair peer-review system, which is all easy to use. Visit http://www.dovepress.com testimonials.php to read real quotes from published authors. 